\title{
Solamargine triggers hepatoma cell death through apoptosis
}

\author{
XIAODONG XIE ${ }^{1}$, HAITAO ZHU $^{1}$, HUIJIAN YANG ${ }^{2}$, WENSI HUANG ${ }^{1}$, YINGYING WU $^{1}$, \\ YING WANG $^{1}$, YANLING LUO ${ }^{1}$, DONGQING WANG ${ }^{1}$ and GENBAO SHAO ${ }^{3}$ \\ ${ }^{1}$ Department of Radiology, The Affiliated Hospital of Jiangsu University, Zhenjiang, Jiangsu 212001; \\ ${ }^{2}$ Department of Immunology, Center of Clinical Medicine and Laboratory; ${ }^{3}$ Department of Biology, \\ School of Medical Science and Laboratory Medicine, Jiangsu University, Zhenjiang, Jiangsu 212013, P.R. China
}

Received May 27, 2014; Accepted March 13, 2015

DOI: $10.3892 / \mathrm{ol} .2015 .3194$

\begin{abstract}
Solamargine (SM), a steroidal alkaloid glycoside extracted from the traditional Chinese herb Solanum incanum, has been evidenced to inhibit the growth and induce apoptosis in a number of human cancer cell lines. In the present study, the anticancer effect of SM and underlying molecular mechanism of SM-induced apoptosis were investigated on the human hepatocellular carcinoma cells, SMMC7721 and HepG2. The proliferation effects of SM on the SMMC7721 and HepG2 cell lines were evaluated using MTT and colony formation assays. In addition, the percentage of apoptosis was measured using an Annexin V/propidium iodide staining method and the cell cycle distribution mediated by SM was analyzed using flow cytometry. The expression levels of B-cell lymphoma-2 (Bcl-2), Bcl-2-associated X protein (Bax), caspase-3, caspase-9, proliferating cell nuclear antigen (pcna) and Ki67 proteins were examined to further demonstrate the proliferate and apoptosis effects of SM on the hepatoma cells. The results indicated that SM effectively inhibited hepatoma cell proliferation and promoted apoptosis. SM resulted in cell cycle arrest at the $\mathrm{G}_{2} / \mathrm{M}$ phase in the two cell lines. In addition, SM downregulated the levels of proliferation-associated (Ki67 and pcna) and anti-apoptotic ( $\mathrm{Bcl}-2)$ proteins, and promoted the activity of apoptosis-associated proteins (Bax, caspase-3 and caspase-9). Therefore, the activation of the Bcl-2/Bax and caspase signaling pathways may be involved in the SM-induced apoptosis of hepatoma cells.
\end{abstract}

Correspondence to: Dr Dongqing Wang, Department of Radiology, The Affiliated Hospital of Jiangsu University, 438 Jiefang Road, Zhenjiang, Jiangsu 212001, P.R. China

E-mail: xiaodong8196@126.com

Dr Genbao Shao, Department of Biology, School of Medical Science and Laboratory Medicine, Jiangsu University, $301 \mathrm{XueFu}$, Zhenjiang, Jiangsu 212013, P.R. China

E-mail: gbshao07@ujs.edu.cn

Key words: solamargine, hepatoma, apoptosis, cell cycle phases

\section{Introduction}

Hepatocellular carcinoma is a common type of malignant liver tumor with $>600,000$ cases diagnosed per year, particularly in Asia and Africa $(1,2)$. The five-year survival rate of this disease is $<9 \%$ (3) and the number of mortalities associated with hepatocellular carcinoma is $>500,000$ patients per year (4). Due to the lack of effective techniques and therapeutic strategies, hepatocellular carcinoma is an important health problem. The current treatment strategies for hepatocellular carcinoma, including the use of chemotherapy, radiotherapy and surgery, are relatively limited. In addition, liver cancer recurrence and metastasis following treatment with the aforementioned strategies are common $(5,6)$. Therefore, it is desirable to develop novel and effective agents with minimum adverse effects for the prevention and treatment of hepatocellular carcinoma.

Apoptosis or programmed cell death plays a significant role in the growth regulation of normal and neoplastic tissues, since it balances cell proliferation (7-9). Cells undergoing apoptosis usually present cell shrinkage, chromatin condensation, nuclear fragmentation and apoptotic bodies $(10,11)$. Apoptosis usually occurs in a well-designed sequence of morphological events mediated by intrinsic and extrinsic pathways, and has been demonstrated to activate the programmed cell death pathway to exert anticancer functions $(12,13)$. Numerous antitumor drugs are known to trigger cell death by inducing apoptosis. In particular, traditional Chinese medicine has been widely used in the treatment of cancer patients, having an effective function $(14,15)$. Solamargine (SM), a member of the Solanaceae (or nightshade) family, is extracted from the Chinese herb Solanum incanum L. and is a major steroidal glycoalkaloids (16). Previous studies have demonstrated that SM strongly inhibits the growth and induces the apoptosis of several human tumor cells, including breast, prostate, colon, lung and hepatoma cancer cells (17-19). Therefore, its marked antitumor activity has received increasing attention. Certain studies have demonstrated the underlying mechanisms of apoptosis induced by SM in human cancer cell lines, including through tumor necrosis factor receptors and mitochondrial release of cytochrome $c$ (20). However, the underlying mechanisms of the effect of SM in hepatoma cancer lines remain unclear. Therefore, the aim of the present study was to observe and detect the effect of SM on the human hepatocellular carcinoma cell lines, SMMC7721 and HepG2. 


\section{Materials and methods}

Materials. SM with a purity of $>98 \%$ was purchased from Yilin Biotechnology Co., Ltd. (Shanghai, China). In addition, MTT and DAPI were purchased from Beyotime Institute of Biotechnology (Shanghai, China). Dulbecco's modified eagle's medium (DMEM) and fetal bovine serum (FBS) were purchased from Gibco Life Technologies (Grand Island, NY, USA). The Annexin V/propidium iodide (PI) Apoptosis Detection kit and the Cell Cycle Analysis kit were obtained from BD Biosciences (San Diego, CA, USA). Rabbit anti-human polyclonal B-cell lymphoma-2 (Bcl-2; 1:1,000; cat. no. 2876S), rabbit anti-human polyclonal $\mathrm{Bcl}-2$-associated $\mathrm{X}$ protein (Bax; 1:1,000; cat. no. 2274S), rabbit anti-human monoclonal caspase-3 (1:1,000; cat. no. 9664S), rabbit anti-human polyclonal caspase-9 (1:1,000; cat. no. 9502S), mouse anti-human monoclonal proliferating cell nuclear antigen (pena; 1:1,000; cat. no. 2586S) and mouse anti-human monoclonal $\beta$-actin (1:1,000; cat. no. 3700S) primary antibodies were obtained from Cell Signaling Technology, Inc. (Beverly, MA, USA). Rabbit anti-human polyclonal Ki67 primary antibody (1:500; cat. no. BA1508) was purchased from Wuhan Boster Biotechnology, Ltd., (Wuhan, China). Horseradish peroxidase (HRP)-conjugated goat anti-rabbit (1:2,000; cat. no. 7071S) and goat anti-mouse (1:2,000; cat. no. 7072S) IgG secondary antibodies, were obtained from Cell Signaling Technology, Inc. All other chemicals used were commercial products of reagent grade.

Cell lines and culture. Human hepatoma cells (SMMC7721 and HepG2) were purchased from the Cell Bank of the Chinese Academy of Sciences (Shanghai, China). The two human hepatoma cell lines were maintained in DMEM supplemented with 10\% FBS, $100 \mathrm{U} / \mathrm{ml}$ penicillin (Gibco Life Technologies) and $100 \mu \mathrm{g} / \mathrm{ml}$ streptomycin (Gibco Life Technologies) in a $37^{\circ} \mathrm{C}$ incubator containing $5 \% \mathrm{CO}_{2}$.

Cytotoxicity and colony formation assay. The cytopathic effects of SM were evaluated in the SMMC7721 and HepG2 cells using an MTT assay, which is a common colorimetric technique used to detect the number of viable cells, cytotoxicity and cell proliferation. $\mathrm{IC}_{50}$ is defined as the concentration of drug causing 50\% inhibition of cell growth compared with the control group. The MTT assay was performed according to the manufacturer's instructions. In the colony-forming assay, the cells were seeded into 6-well culture plates at a low density of 500 cells/well, treated with various concentrations of SM $(5,10$ or $20 \mu \mathrm{M})$ and incubated for two weeks. Subsequently, the cells were fixed with $4 \%$ paraformaldehyde and stained with Giemsa (Beyotime Institute of Biotechnology). Images were then captured using a fluorescence microscope (Eclipse TS100; Nikon Corporation, Tokyo, Japan) and the clonogenicity was determined.

\section{Detection of apoptosis}

Cell and cell nucleus morphological changes. SMMC7721 and HepG2 cells (1x10\% then treated with SM $(20 \mu \mathrm{M})$ for $24 \mathrm{~h}$. The cell morphological changes were observed using a light microscope (CHK-213; Olympus Corporation, Tokyo, Japan). For fluorescent staining, the samples were treated with $20 \mu \mathrm{M} \mathrm{SM}$ for $24 \mathrm{~h}$, fixed with ice-cold $4 \%$ paraformaldehyde and stained with $1 \mu \mathrm{g} / \mathrm{ml}$ DAPI for $10 \mathrm{~min}$. Subsequently, images were captured using a fluorescence microscope (Eclipse TS100; Nikon Corporation).

Apoptosis ratio of SM-treated cells. The apoptotic ratio was detected using an Annexin V/PI method (21). Briefly, the cells were treated with various concentrations of SM $(0,5,10$ or $20 \mu \mathrm{M})$ for $24 \mathrm{~h}$, trypsinized (Gibco Life Technologies) and resuspended in $100 \mu \mathrm{l}$ binding buffer, followed by addition of $5 \mu \mathrm{l}$ Annexin V and PI in each tube. Next, $400 \mu \mathrm{l}$ binding buffer was added to each reaction tube and the cells were collected for further analysis.

Cell cycle analysis. Detection of the cell cycle distribution was performed following the addition of $20 \mu \mathrm{M}$ SM for $24 \mathrm{~h}$. The cells were harvested using trypsinization, fixed with $4 \%$ paraformaldehyde for $30 \mathrm{~min}$ and then washed with phosphate-buffered saline (PBS). Next, the samples were centrifuged for $10 \mathrm{~min}$ at a speed of $91 \mathrm{x}$ g. Subsequently, the cells were stained with $0.5 \mathrm{mg} / \mathrm{ml}$ PI containing $0.5 \mathrm{mg} / \mathrm{ml}$ RNase (BD Biosciences, Franklin Lakes, NJ, USA) at $4^{\circ} \mathrm{C}$ for $30 \mathrm{~min}$. The DNA content was then measured with a FACScan flow cytometer (BD Biosciences).

Western blot analysis. Following SM treatment for $24 \mathrm{~h}$, the cells were washed with ice-cold PBS twice. Cell lysates were collected using a lysis buffer (Beyotime Institute of Biotechnology) and the cell lysate proteins were loaded and separated using SDS-PAGE. Next, the samples were transferred onto polyvinylidene difluoride membranes and incubated in PBS containing 3\% bovine serum albumin (BSA) for $1 \mathrm{~h}$ at room temperature. Antibodies in Tris-buffered saline/Tween 20 (TBST) with 1\% BSA were then added and the membranes were incubated at $4^{\circ} \mathrm{C}$ overnight. Subsequently, the membranes were washed with TBST and incubated with the secondary antibody for $1 \mathrm{~h}$ at room temperature. Immunoreactive bands were detected using an enhanced chemiluminescence reagent (EMD Millipore, Billerica, MA, USA) and all the blots were quantified using LANE 1D software (Sage Creation Science Co., Ltd., Beijing, China).

Statistical analysis. All the data are expressed as the mean \pm standard deviation and the differences between two groups were analyzed using Student's t-test. All statistical analyses were performed using SPSS 16.0 software (SPSS, Inc., Chicago, IL, USA). $\mathrm{P}<0.05$ was considered to indicate a statistically significant difference. All the experiments were performed at least in triplicate.

\section{Results}

Proliferation of hepatoma cells is inhibited by SM. The inhibition of hepatoma cell proliferation was determined using an MTT assay. As shown in Fig. 1A and B, the time-survival curve was constructed following treatment of each cell line with 5,10 or $20 \mu \mathrm{M} \mathrm{SM}$. At the 3, 6, 12, 24 and $48 \mathrm{~h}$ time points, the ratio of cell survival was found to slightly change with time; however, cell survival was mainly dose-dependent. The minimum survival rate was detected at $20 \mu \mathrm{M}$ SM treatment for $48 \mathrm{~h}$ in the SMMC7721 and HepG2 cells. The $\mathrm{IC}_{50}$ 
A

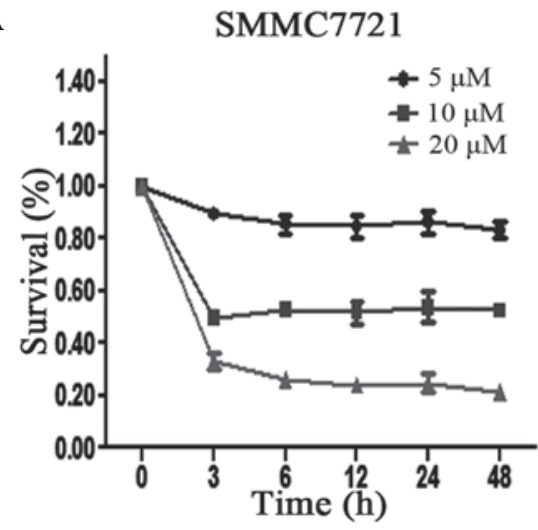

B

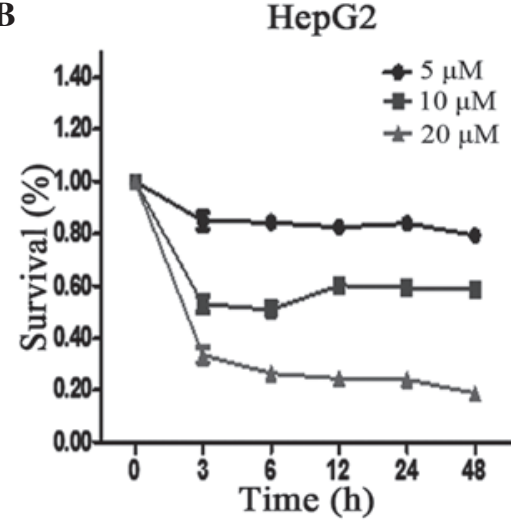

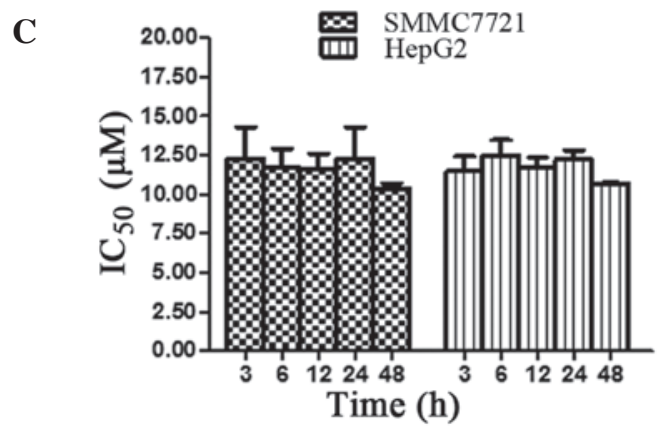

Figure 1. SM suppressed cell viability of SMMC7721 and HepG2 cells. Cell viability was examined using an MTT assay. (A) SMMC7721 and (B) HepG2 cell lines were treated with 5, 10 and $20 \mu \mathrm{M} \mathrm{SM}$ for 3,6,12,24 or $48 \mathrm{~h}$. (C) $\mathrm{IC}_{50}$ values of SM were calculated at different treatment time intervals. No statistically significant differences were observed between different time points. The ratio of cell survival changed in a dose-dependent manner. Data are presented as the mean \pm standard deviation of three independent experiments. SM, solamargine; $\mathrm{IC}_{50}$, concentration of drug causing $50 \%$ inhibition of cell growth.

A

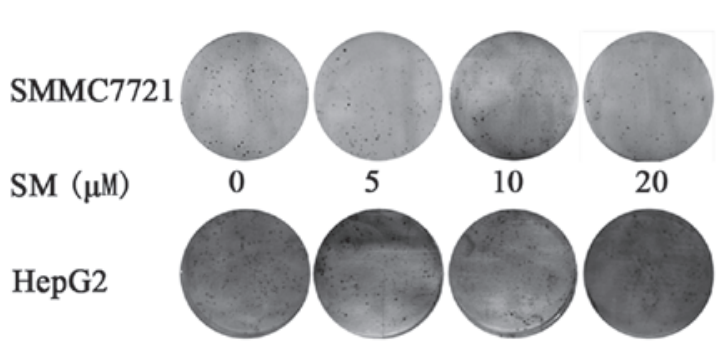

B

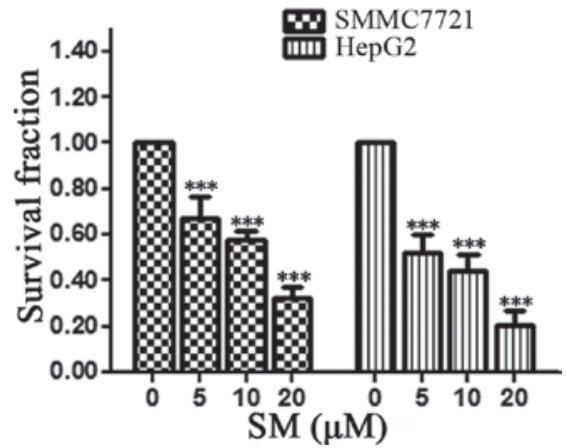

Figure 2. SMMC7721 and HepG2 cells were treated with 0, 5, 10 and $20 \mu \mathrm{M} \mathrm{SM}$ for $24 \mathrm{~h}$. (A) Images of cell count following SM treatment, showing significantly reduced cell proliferation and decreased clonogenicity, which were greater upon treatment with increased SM concentration. (B) Survival fraction in the two cell lines. The results are presented as the mean \pm standard deviation. ${ }^{*} \mathrm{P}<0.05,{ }^{* *} \mathrm{P}<0.01$ and ${ }^{* * * *} \mathrm{P}<0.001$, vs. $0 \mu \mathrm{M}$ SM group. SM, solamargine.

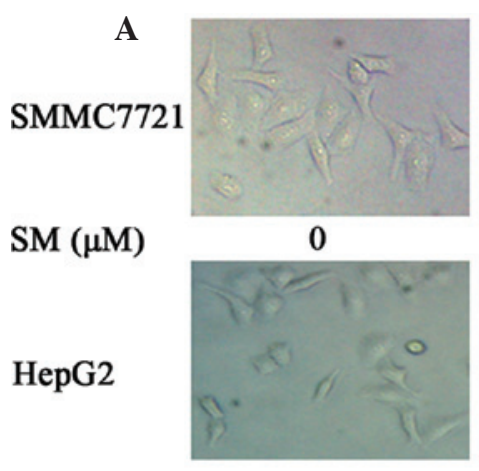

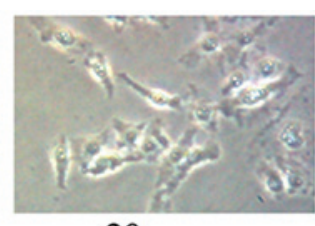

20

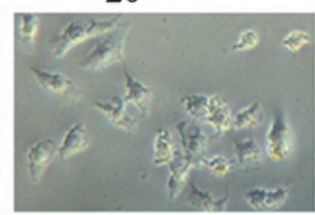

B

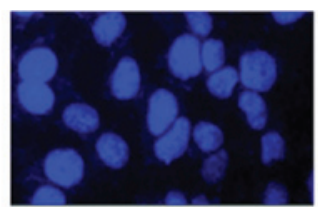

0

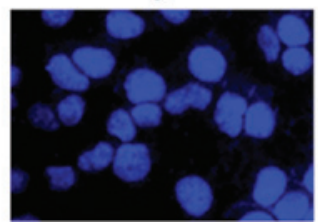

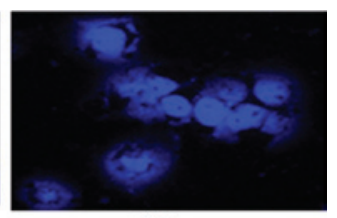

20

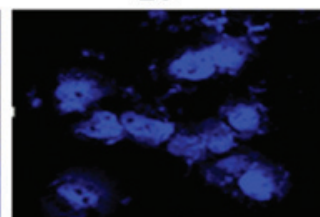

Figure 3. (A) Morphology of SMMC7721 and HepG2 cells treated with $20 \mu \mathrm{M} \mathrm{SM}$ for $24 \mathrm{~h}$ (magnification, $\mathrm{x} 40$ ). In the two cell lines, the cells were evidently reduced in size and their margins were unclear compared with the control group. (B) Morphological changes of the nuclear chromatin following $20 \mu \mathrm{M}$ SM treatment for $24 \mathrm{~h}$. The cells were stained with DAPI and observed using a fluorescence microscope. The SM-treated cells presented nuclear chromatin condensation and fragmentation. SM, solamargine. 
A
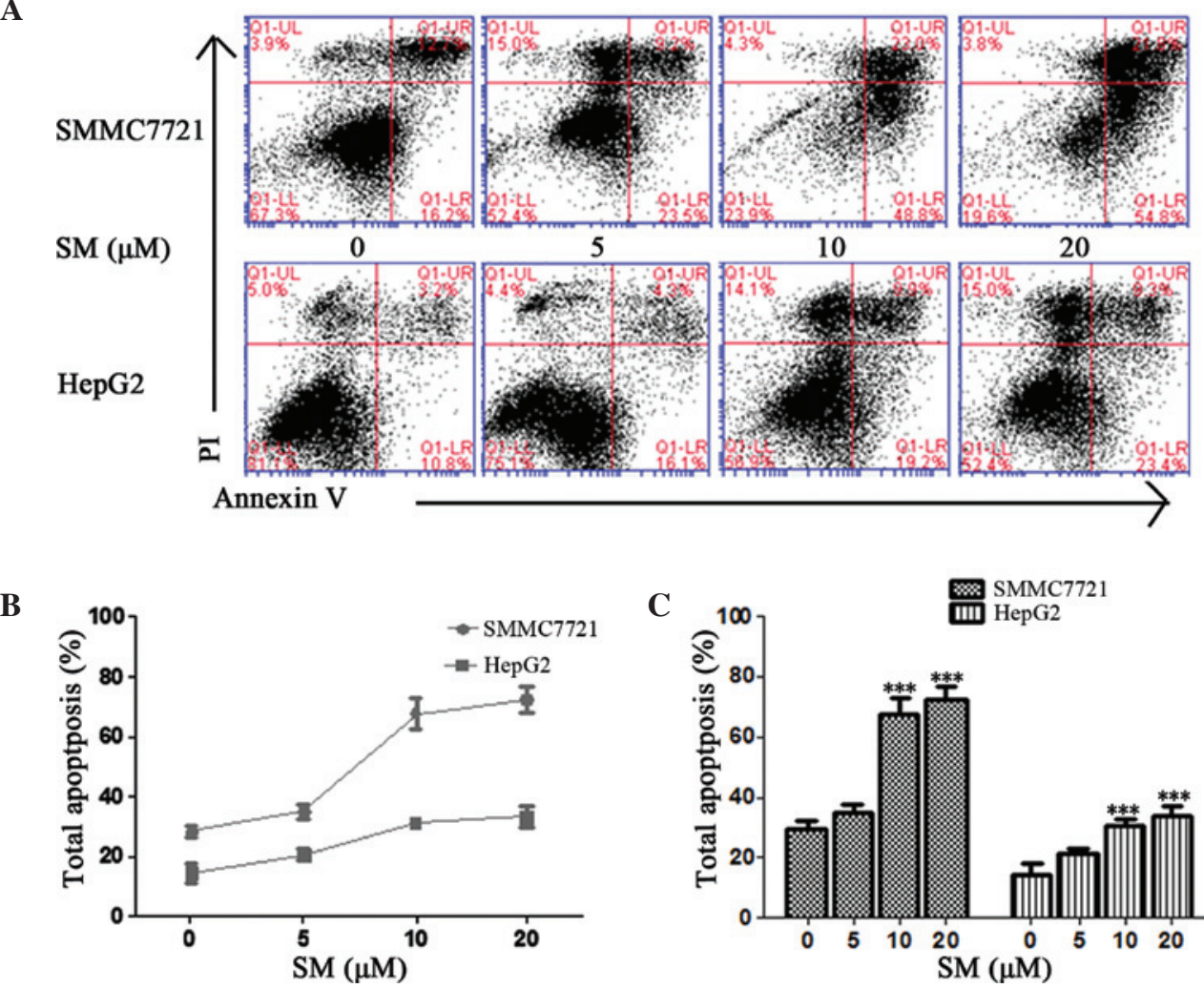

Figure 4. SMMC7721 and HepG2 cells treated with 0, 5, 10 and $20 \mu \mathrm{M}$ SM for $24 \mathrm{~h}$. (A) The cells were stained with Annexin V and PI. The percentages of early and late apoptosis were based on the cells present in the LR and UR quadrants. (B) Total apoptosis percentage, indicating that SM induced apoptosis in a dose-dependent manner. (C) Statistical analysis of total apoptosis percentage. At $5 \mu \mathrm{M}$ SM, no significant differences were observed compared with the control group ( $\mathrm{P}>0.05)$. At 10 and $20 \mu \mathrm{M},{ }^{* * * *} \mathrm{P}<0.001$ vs. the control group. SM, solamargine; PI, propidium iodide; LR, lower right; UR, upper right.

values of the SMMC7721 cells were $12.27,11.86,11.57,12.17$ and $10.48 \mu \mathrm{M}$ following treatment for $3,6,12,24$ and $48 \mathrm{~h}$, respectively. However, no statistically significant differences were detected among the different time points $(\mathrm{P}>0.05$; Fig. 1C). Similar results were obtained for the HepG2 cell line, which confirmed the results of the SMMC7721 cells.

Clonogenicity of hepatoma cells is decreased by SM. For the colony formation assay, 500 SMMC7721 cells were seeded onto a 6-well plate and incubated for two weeks; next, images were captured and the cell spheres were counted, as shown in Fig. 2A. Compared with the untreated group ( $0 \mu \mathrm{M} \mathrm{SM})$, the survival fractions were $52.6,42.1$ and $26.3 \%$ of cells following 24-h exposure to 5, 10 and $20 \mu \mathrm{M} \mathrm{SM}$, respectively. The results demonstrated that the density and number of cell spheres significantly decreased with increasing SM concentration $(\mathrm{P}<0.001$; Fig. $2 \mathrm{~B})$. The HepG2 cells exhibited a similar pattern following SM treatment.

SM induces cell and cell nucleus morphological changes due to apoptosis. Following cell treatment with $20 \mu \mathrm{M} \mathrm{SM}$ for $24 \mathrm{~h}$, changes in the cell morphology were observed using a microscope. As shown in Fig. 3A, the cells were evidently reduced in size and their margins were unclear, with certain parts of the cells appearing smaller and rounder when compared with the control group. Following DAPI staining, the SM-treated cells presented nuclear chromatin condensation and fragmentation, as shown in Fig. 3B. Similar results were obtained for the two cell lines, SMMC7721 and HepG2. These results indicated that the SM-treated hepatoma cells presented cellular features of apoptosis.

Ratio of SM-induced apoptosis in hepatoma cells. The ratio of SM-induced apoptosis was detected using an Annexin V/PI method. Early and late apoptosis percentages were determined based on the cells present in the lower right (LR) and upper right (UR) quadrants of the graphs, respectively (Fig. 4A). The total percentages of SM-induced apoptosis in the SMMC7721 cells were $28.9,32.7,71.8$ and $76.6 \%$ following exposure to $0,5,10$ and $20 \mu \mathrm{M} \mathrm{SM}$, respectively, for $24 \mathrm{~h}$ (Fig. 4A); therefore, the effect of SM was dose-dependent (Fig. 4B and C). At a concentration of $5 \mu \mathrm{M} \mathrm{SM}$, the total apoptosis percentage was found to be slight increased, but the difference was not statistically significant ( $\mathrm{P}>0.05$; Fig. 4C). By contrast, the apoptosis induced in the 10 and $20 \mu \mathrm{M}$ SM-treated cells was evidently increased when compared with the untreated cells and demonstrated statistically significant differences $(\mathrm{P}<0.001$; Fig. 4C). HepG2 cells exhibited a similar pattern following SM treatment.

$S M$ arrests cell cycle at $G_{2} / M$ phase. The distribution of the cell cycle was detected using a FACScan flow cytometer and is shown in Fig. 5A. In SMMC7721 cells treated with $20 \mu \mathrm{M}$ $\mathrm{SM}$, the percentage of cells at the $\mathrm{G}_{0} / \mathrm{G}_{1}$ phase ranged between $54.92 \%(0 \mu \mathrm{M} \mathrm{SM})$ and $50.98 \%(20 \mu \mathrm{M} \mathrm{SM})$, while at the $\mathrm{S}$ phase it varied between 32.29 and $28.44 \%$. By contrast, the percentage of cells at the $\mathrm{G}_{2} / \mathrm{M}$ phase increased from $12.79 \%$ (0 $\mu \mathrm{M} \mathrm{SM})$ to $20.57 \%$ (20 $\mu \mathrm{M} \mathrm{SM})$. The results revealed that 
A
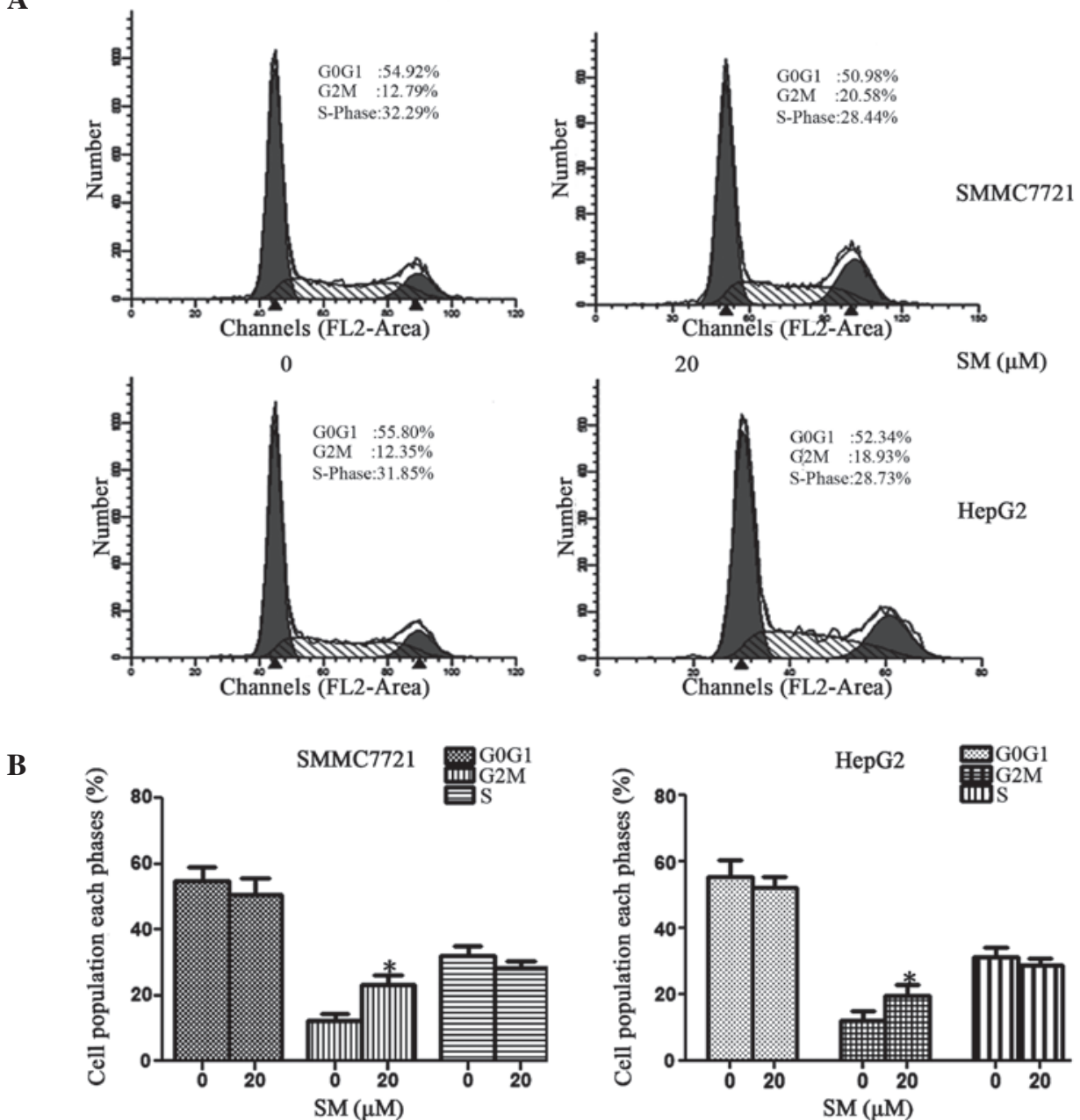

Figure 5. (A) Cell cycle analysis by flow cytometry for SMMC7721 and HepG2 cells treated with $20 \mu \mathrm{M} \mathrm{SM}$. (B) Statistical results of cell cycle analysis. SM-treated cells exhibited cell cycle arrest at $\mathrm{G}_{2} / \mathrm{M}$ phase ( ${ }^{*} \mathrm{P}<0.05$ vs. $0 \mu \mathrm{M}$ SM group). SM, solamargine.

A

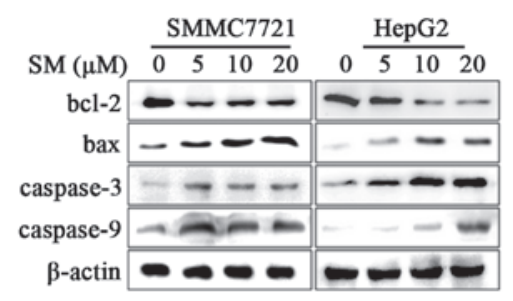

C

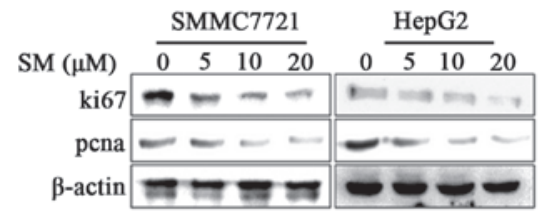

$\mathbf{B}$
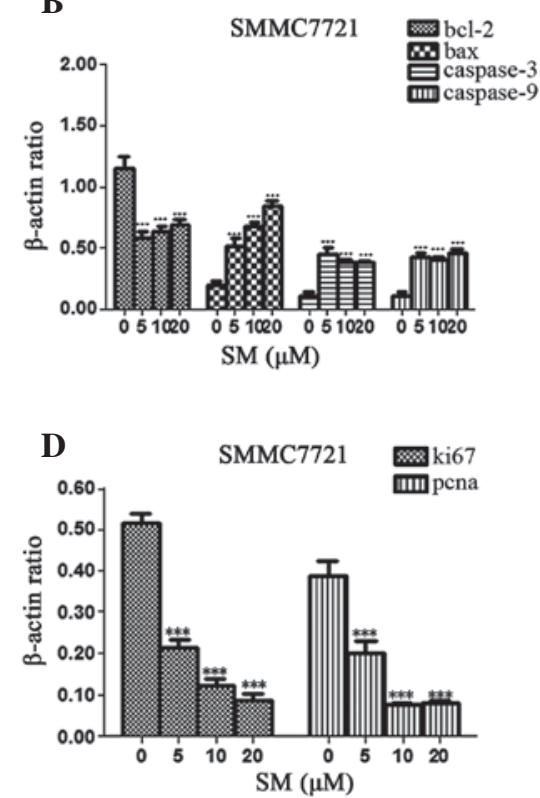
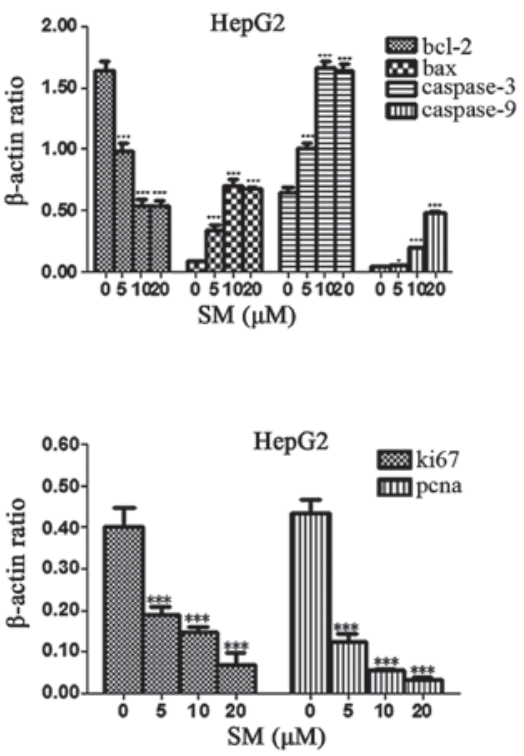

Figure 6. (A) Expression of apoptosis-associated proteins in SMMC7721 and HepG2 cells treated with SM and (B) the statistical results of this analysis. The expression levels of Bcl-2, Bax, caspase- 3 and caspase- 9 were detected by western blot analysis using $\beta$-actin as a control. (C) Expression levels of proliferation-associated proteins, ki67 and pcna, also investigated by western blot analysis and (D) the statistical results of this analysis. The results are representative of at least three independent experiments. SM, solamargine. 
SM may induce $\mathrm{G}_{2} / \mathrm{M}$ phase arrest, with almost no effect on $\mathrm{G}_{0} / \mathrm{G}_{1}$ and $\mathrm{S}$ phases, as shown in Fig. 5B. Similar results were also achieved in the HepG2 cell line.

Expression of apoptosis- and proliferation-associated proteins in SM-treated cells. The apoptosis-associated proteins were detected in order to determine the signaling pathway responsible for the apoptosis in SM-treated cells. Western blot analysis revealed that the expression levels of Bax, caspase-3 and caspase-9 in SM-treated cells were evidently upregulated when compared with the control group. By contrast, the Bcl-2 protein expression levels were significantly downregulated when compared with the control group. The Bcl-2, Bax, caspase- 3 and caspase- 9 protein expression levels were affected in a dose-dependent manner in the HepG2 cell lines (Fig. 6A and B). In addition, the expression levels of Bcl-2 were signficantly downregulated and the expression levels of Bax, caspase- 3 and caspase- 9 were evidently upregulated in the SM-treated SMMC7721 cells when compared with the control group (Fig. 6A and B). The results revealed that SM increased the activity of the apoptosis-associated proteins. In addition, the proliferation-associated proteins, Ki67 and pcna, were also examined and the two cell lines demonstrated a decrease in the protein expression levels in a dose-dependent manner (Fig. 6C and D). Therefore, SM inhibited the cell proliferation and assisted the promotion of apoptosis.

\section{Discussion}

Chinese herbs consist of various active components and have a particular function in the regulation of cell behavior, with their effectiveness proven in a number of in vivo studies and clinical trials $(22,23)$. Solamargine (SM), which is purified from Solanum incanum, has been demonstrated to possess a number of pharmacological properties and is one of the most promising agents for the treatment of various cancer types. However, the molecular mechanism through which SM affects liver cancer cells remains to be clarified. The present study demonstrated that SM may inhibit cell proliferation and promote apoptosis in human hepatoma cells.

In the current study, the results of the MTT assay confirmed that SM effectively reduced the cell viability and proliferation in a dose-dependent manner in the SMMC7721 and HepG2 cell lines. A colony formation assay further demonstrated that SM inhibited the growth and cell clonogenicity of hepatoma cells in a concentration-dependent manner. In addition, certain studies have previously reported that SM inhibited cell proliferation in different cancer cell lines in a dose-dependent manner (24-26), which is consistent with the results of the present study.

Cell cycle is a vital biological process that regulates the growth and metabolism of the human body (27-29). In the present study, the effect of SM on the cell cycle was investigated. SM was identified to affect the cell cycle distribution and arrest the cell cycle at the $\mathrm{G}_{2} / \mathrm{M}$ phase, with only a limited effect on the $G_{0} / G_{1}$ and $S$ phases. According to these results, the SM-induced proliferation inhibition in hepatoma cells was hypothesized to be associated with the induction of $\mathrm{G}_{2} / \mathrm{M}$ arrest.Furthermore, the expression of proliferation-associated proteins, Ki67 and pcna, was investigated. Ki67 is a nuclear protein expressed during cellular proliferation, particularly during the mitosis phase (30), while pcna has been identified as a nuclear antigen observed in the $\mathrm{S}$ phase (31). Ki67 and pcna are effective markers used to determine the growth capacity of a cell population (32). In the present study, the western blot analysis results demonstrated that Ki67 and pcna were downregulated following exposure to SM, which indicated that the hepatoma cell capacity of proliferation was inhibited following treatment with SM, when compared with the untreated group. Furthermore, the present study proposed that SM suppressed cell growth, assisting the promotion of apoptosis.

The cell morphology was observed and DAPI staining indicated that SMMC7721 and HepG2 cells treated with SM demonstrated cellular features of apoptosis. Subsequently, the percentages of early and late apoptosis were distinguished using an Annexin V and PI method, which identified an increasing trend (Fig. 4B). Upon treatment with $5 \mu \mathrm{M} \mathrm{SM}$, the percentage of total apoptosis increased, but the difference was not statistically significant compared with the untreated group $(\mathrm{P}>0.05)$. Therefore, this $\mathrm{SM}$ concentration was hypothesized to be relative low and unable to trigger further cell apoptosis that would be detected by Annexin V and PI. By contrast, at 10 and $20 \mu \mathrm{M}$ SM, the apoptosis rate was identified to be significantly different compared with the control group $(\mathrm{P}<0.001)$. In order to clarify the exact mechanism of apoptosis in hepatoma cells, the expression levels of Bcl-2 family proteins and caspases were examined $(33,34)$. $\mathrm{Bcl}-2$ family proteins play a crucial role in the mitochondrial apoptosis pathway, and the $\mathrm{Bax} / \mathrm{Bcl}-2$ ratio reflects a close association to the extent of apoptosis $(35,36)$. According to the results of the present study, SM downregulated the expression of Bcl-2 and upregulated the expression of Bax, which indicated that $\mathrm{Bcl}-2$ family proteins are involved in the SM triggered apoptosis in SMMC7721 and HepG2 cells. Furthermore, caspases are key factors in the execution of apoptosis (37-39), with the present results demonstrating that the expression levels of caspase- 3 and caspase- 9 were elevated following SM treatment. These results revealed that the activation of the $\mathrm{Bcl}-2 / \mathrm{Bax}$ and caspase signaling pathways is involved in the SM-induced apoptosis of hepatoma cells.

In conclusion, SM plays a crucial role in triggering hepatoma cell death through apoptosis. In addition, SM was identified to effectively reduce the growth and induce cell cycle arrest at the $\mathrm{G}_{2} / \mathrm{M}$ phase, which promoted apoptosis. The present study aimed to provide a novel therapeutic agent for the treatment of hepatocellular carcinoma. However, to the best of our knowledge, numerous mechanisms are involved in SM-induced apoptosis and further research is required to elucidate these.

\section{Acknowledgements}

This study was supported by grants from the Natural Science Foundation of Jiangsu Province (no. BK2011487), the National Natural Science Foundation of China (no. 81170573) and the Social Development Foundation of Zhenjiang City (no. SZC201130128). 


\section{References}

1. Di Bisceglie AM, Rustgi VK, Hoofnagle JH, Dusheiko GM and Lotze MT: NIH conference, Hepatocellular carcinoma. Ann Intern Med 108: 390-401, 1988.

2. Chen JG and Zhang SW: Liver cancer epidemic in China: past, present and future. Semin Cancer Biol 21: 59-69, 2011.

3. Poupon R, Fartoux L and Rosmorduc O: Therapeutic advances in hepatocellular carcinoma. Bull Acad Natl Med 192: 23-31, 2008 (In French).

4. Bosch FX, Ribes J and Borràs J: Epidemiology of primary liver cancer. Semin Liver Dis 19: 271-285, 1999.

5. Forner A, Hessheimer AJ, Isabel Real M and Bruix J: Treatment of hepatocellular carcinoma. Crit Rev Oncol Hematol 60: 89-98, 2006.

6. Jakobs TF, Hoffmann RT, Tatsch K, Trumm C and Reiser MF: Therapy response of liver tumors after selective internal radiation therapy. Radiologe 48: 839-849, 2008 (In German).

7. Fadeel B and Orrenius S: Apoptosis: a basic biological phenomenon with wide-ranging implications in human disease. J Intern Med 258: 479-517, 2005.

8. Jacobson MD, Weil M and Raff MC: Programmed cell death in animal development. Cell 88: 347-354, 1997.

9. Ghobrial IM, Witzig TE and Adjei AA: Targeting apoptosis pathways in cancer therapy. CA Cancer J. Clin 55: 178-194, 2005

10. Kerr JF: Shrinkage necrosis: a distinct mode of cellular death. J. Pathol 105: 13-20, 1971.

11. Searle J, Kerr JF and Bishop CJ: Necrosis and apoptosis: distinct modes of cell death with fundamentally different significance. Pathol Annu 17: 229-259, 1982

12. Rich T, Watson CJ and Wyllie A: Apoptosis: the germs of death. Nat Cell Biol 1: E69-E71, 1999.

13. Hu W and Kavanagh JJ: Anticancer therapy targeting the apoptotic pathway. Lancet Oncol 4: 721-729, 2003.

14. McCulloch M, See C, Shu XJ, et al: Astragalus-based Chinese herbs and platinum-based chemotherapy for advanced non-small-cell lung cancer: meta-analysis of randomized trials. J Clin Oncol 24: 419-430, 2006.

15. Mok TS, Yeo W, Johnson PJ, et al: A double-blind placebo-controlled randomized study of Chinese herbal medicine as complementary therapy for reduction of chemotherapy-induced toxicity. Ann Oncol 18: 768-774, 2007.

16. Lorey S, Porzel A and Ripperger H: Steroid alkaloid glycosides from Solanum coccineum. Phytochemistry 41: 1633-1635, 1996.

17. Son YO, Kim J, Lim JC, Chung Y, Chung GH and Lee JC: Ripe fruit of Solanum nigrum L. inhibits cell growth and induces apoptosis in MCF-7 cells. Food Chem Toxicol 41: 1421-1428, 2003

18. Li J, Li Q, Feng T and Li K: Aqueous extract of Solanum nigrum inhibit growth of cervical carcinoma (U14) via modulating immune response of tumor bearing mice and inducing apoptosis of tumor cells. Fitoterapia 79: 548-556, 2008.

19. Hu K, Kobayashi H, Dong A, Jing Y, Iwasaki S and Yao X: Antineoplastic agents. III: Steroidal glycosides from Solanum nigrum. Planta Med 65: 35-38, 1999.

20. Shiu LY, Chang LC, Liang CH, Huang YS, Sheu HM and Kuo $\mathrm{KW}$ : Solamargine induces apoptosis and sensitizes breast cancer cells to cisplatin: Food Chem Toxicol 45: 2155-2164, 2007.

21. Liu T, Zhu W, Yang X, et al: Detection of apoptosis based on the interaction between annexin V and phosphatidylserine. Anal Chem 81: 2410-2413, 2009.
22. Lam W, Bussom S, Guan F, et al: The four-herb Chinese medicine PHY906 reduces chemotherapy-induced gastrointestinal toxicity. Sci Trans Med 2: 45ra59, 2010.

23. Chen W, Lim CE, Kang HJ and Liu J: Chinese herbal medicines for the treatment of type A H1N1 influenza: a systematic review of randomized controlled trials. PLoS One 6: e28093, 2011.

24. Ding X, Zhu FS, Li M and Gao SG: Induction of apoptosis in human hepatoma SMMC-7721 cells by solamargine from Solanum nigrum L. J Ethnopharmacol 139: 599-604, 2012.

25. Sun L, Zhao Y, Li X, Yuan H, Cheng A and Lou H: A lysosomal-mitochondrial death pathway is induced by solamargine in human K562 leukemia cells. Toxicol In Vitro 24: 1504-1511, 2010.

26. Li X, Zhao Y, Wu WK, Liu S, Cui M and Lou H: Solamargine induces apoptosis associated with p53 transcription-dependent and transcription-independent pathways in human osteosarcoma U2OS cells. Life Sci 88: 314-321, 2011.

27. Baggett D, Nakaya MA, McAuliffe M, Yamaguchi TP and Lockett S: Whole cell segmentation in solid tissue sections. Cytometry A 67: 137-143, 2005.

28. Dormann D, Libotte T, Weijer CJ and Bretschneider T: Simultaneous quantification of cell motility and protein-membrane-association using active contours. Cell Motil Cytoskeleton 52: 221-230, 2002.

29. Liu B, Cheng HD, Huang J, et al: Probability density difference-based active contour for ultrasound image segmentation. Pattern Recognit 43: 2028-2042, 2010.

30. Beresford MJ, Wilson GD and Makris A: Measuring proliferation in breast cancer:practicalities and applications. Breast Cancer Res 8: 216, 2006.

31. Leonardi E, Girlando S, Serio G, et al: PCNA and Ki67 expression in breast carcinoma: correlations with clinical and biological variables. J Clin Pathol 45: 416-419, 1992.

32. Scholzen T and Gerdes J: The Ki-67 protein: from the known and the unknown. J Cell Physiol 182: 311-322, 2000.

33. Zhang N, Wang X, Huo Q, et al: The oncogene metadherin modulates the apoptotic pathway based on the tumor necrosis factor superfamily member TRAIL (Tumor Necrosis Factor-related Apoptosis-inducing Ligand) in breast cancer. J Biol Chem 288: 9396-9407, 2013.

34. Chan SL and Yu VC: Proteins of the bcl-2 family in apoptosis signalling: from mechanistic insights to therapeutic opportunities. Clin Exp Pharmacol Physiol 31: 119-128, 2004.

35. Reyes-Zurita FJ, Rufino-Palomares EE, Lupiáñez JA and Cascante M: Maslinic acid, a natural triterpene from Olea europaea L, induces apoptosis in HT29 human colon-cancer cells via the mitochondrial apoptotic pathway. Cancer Lett 273: 44-54, 2009

36. Adams JM and Cory S: The Bcl-2 protein family: arbiters of cell survival. Science 281: 1322-1326, 1998.

37. Zhang N, Kong X, Yan S, Yuan C and Yang Q: Huaier aqueous extract inhibits proliferation of breast cancer cells by inducing apoptosis. Cancer Sci 101: 2375- 2383, 2010.

38. Antonsson B: Bax and other pro-apoptotic Bcl-2 family 'killer-proteins' and their victim the mitochondrion. Cell Tissue Res 306: 347-361, 2001.

39. Crompton M: Bax, Bid and the permeabilization of the mitochondrial outer membrane in apoptosis. Curr Opin Cell Biol 12: 414-419, 2000 